\title{
SUBLIMAÇÃO EM PSICANÁLISE: CONTRIBUIÇÕES PARA CONSTRUÇÃO DE UMA NOVA METODOLOGIA EM DESIGN.
}

\author{
Danielle Spada Tavares \\ Mestre em Psicanálise, Saúde e Sociedade - Universidade Veiga de Almeida \\ ccearte@gmail.com
}

Resumo: Ao aproximar dois campos distintos do saber, design e psicanálise, este artigo relaciona a importância da subjetividade no processo de criação com a particularidade valorizada e determinante na construção metodológica dos projetos em design. A criação artística é vista como paradigma para metodologia projetual através do destino pulsional sublimatório. A primeira parte do artigo apresenta a sublimação como operação pela qual um objeto comum é elevado a dignidade de objeto de design; a segunda parte mostra os processos inconscientes como diferencial no processo metodológico em design; por fim, é apresentada uma reflexão sobre a dimensão subjetiva de algumas ferramentas de criatividade utilizadas no processo metodológico em design.

Palavras-chave: Design, metodologia, criatividade e sublimação.

Abstract: With the approach of two separate fields of knowledge, design and psychoanalysis, this article relates the importance of subjectivity in the creation process with valued and crucial feature of the methodological construction projects in design. Artistic creation is seen as a paradigm for projetual methodology through sublimate instinctual destination. The first part of the article presents as sublimation process by which a common object is elevated to the dignity of design object; the second part shows unconscious processes as differential methodological process design; Finally, a reflection on the subjective dimension of some creativity tools used in the process design methodology is presented.

Keywords: Design, methodology, creativity and sublimation.

\section{INTRODUÇÃO}

Este artigo surgiu da necessidade do desenvolvimento de uma nova metodologia para o ensino de design. Sua organização se deu através de pesquisas e experimentações apoiadas na psicanálise, cujo objetivo era compreender a natureza da criação artística sob o olhar psicanalítico para enriquecer a metodologia projetual em design.

O desenvolvimento desta metodologia encontrou na psicanálise, uma operação fundamental para entender a criação no design: a sublimação. 0 desenvolvimento deste trabalho se apoiou nos estudos de Freud e Lacan sobre a criação artística ao utilizar o objeto de arte, resultado da operação sublimatória, como 
paradigma do objeto de design. A sublimação é uma operação dentro do processo de criar que se sustenta nas pulsões e desejos do sujeito criador, neste caso o designer.

Ao criar e projetar objetos de design ${ }^{1}$, o designer desperta desejos. O desejo é o motor que alimenta o processo criativo tanto nos designers quanto nos sujeitos que consomem estes objetos criados. O que está oculto nos métodos pelos quais esses objetos são projetados foi o ponto inicial do estudo proposto. A criação pela via da sublimação está amarrada ao sujeito naquilo que ele tem de mais íntimo e, ao mesmo tempo, inapreensível, sua subjetividade. Deste modo essa parte particular do sujeito enriquece o método projetual à medida que ele descobre sua própria metodologia.

Os resultados dessa pesquisa mostraram que, ao estimular o sujeito para elaboração do seu próprio processo, ao invés de adaptar-se aos métodos e modelos existentes, ele se torna autor de sua própria forma de fazer, estimulando o nascimento de novas ideias e estruturas para compor uma nova forma de projetar, podendo assim, através do despertar do desejo, oferecer aos sujeitos consumidores dos objetos de design algo que estes nem sabiam que necessitavam.

\section{SUBLIMAÇÃO}

Ao aproximar a metodologia projetual à criação artística se faz necessário compreender o ponto central de tal proposta: a sublimação. Nesta parte do artigo será apresentado o conceito de sublimação em Freud e seu desdobramento em Lacan para entender o processo inconsciente que eleva um objeto comum à dignidade de objeto de design. O que eleva um objeto cotidiano qualquer à dignidade da Coisa é a sublimação. É ela que dignifica um objeto qualquer para que nos provoque uma sensação de gozo através da transformação em objeto artístico. “(...) E a fórmula geral que Ihes dou da sublimação é esta - ela eleva um objeto à dignidade da Coisa". (LACAN, 1959-1960, p.198).

$\mathrm{Na}$ perspectiva psicanalítica, em relação à criação, temos a primeira abordagem teórica elaborada por Freud a partir da apresentação da ideia de sublimação referente à criação artística na qual o processo criativo se inclui. A sublimação para o autor, é um destino pulsional de origem sexual em busca de satisfação. Para Freud, a pulsão está na hiância entre o psíquico e o somático. Ele nos diz que não existe um caminho natural para a sexualidade humana. Não há uma maneira única de satisfazer o desejo, o que confere ao humano a sina de estar sempre insatisfeito frente a este. É em nome desses desvios que Freud fala em pulsão sexual (trieb). A pulsão é uma força constante (konstant kraft), mantém um dispêndio permanente de energia em direção ao objetivo. (FREUD, 1926, p. 181).

$\mathrm{Na}$ criação, há um desvio das pulsões sexuais pelo caminho sublimatório. Ocorre uma mudança de objeto para um socialmente valorizado, ainda que a definição da sublimação esteja diretamente atrelada à mudança em relação ao alvo de satisfação sexual.

Acompanhe o gráfico a seguir:

\footnotetext{
${ }^{1}$ Entende-se por objetos de design, não apenas o objeto no sentido do produto feito, mas engloba o projeto de design em produtos, bens ou serviços, que sejam capazes de estabelecer ligações com seus utilizadores através da usabilidade, da estética, da forma, da interatividade, da emoção onde os aspectos intangíveis são tão importantes quanto os tangíveis.
} 


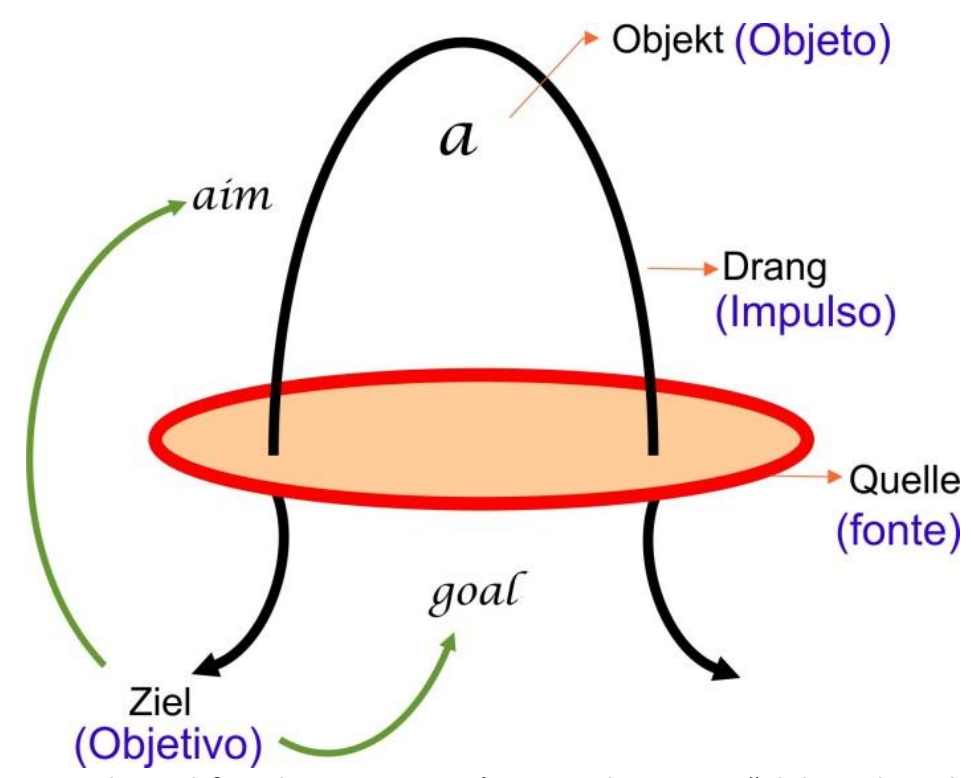

Figura 1 - Circuito Pulsional freudiano com acréscimos de Lacan. “Elaborado pela autora, com base na pesquisa realizada".

Consideremos o circuito da pulsão uma montagem, vários elementos fazendo um grande esforço para se juntar de alguma maneira.

A fonte é a borda, o processo somático que ocorre em um orifício do corpo e cujo estimulo é representado na vida mental por uma pulsão (trieb). É por onde o corpo troca como mundo que o envolve. É o que há de mais íntimo na relação dos orifícios do corpo físico com o mundo que está fora. É uma troca. Da fonte parte o (drang), esforço ou impulso: força que se locomove em direção ao objeto. Esse impulso vai em direção ao objeto (objekt). O objeto original para a pulsão, aquele objeto primeiro que teria existido, é um objeto para sempre perdido por definição. 0 primeiro objeto de satisfação já nasce perdido, porque quando ele é reconstituído pela ativação da marca de memória, é porque já foi perdido, então todo objeto é um substituto desse objeto original que na verdade não existe (das Ding). É uma substituição de algo impossível de se ter de novo, já que nunca existiu. O objetivo (ziel) da pulsão é sempre a satisfação, sendo que a satisfação é definida como a redução da tensão provocada pelo impulso.

A realidade que tentamos delimitar mediante o termo sublimação consiste em admitir que a energia pulsional possa abstrair-se do seu contexto sexual. Dessexualizar-se seria separar-se de sua fonte, de seu objeto e de sua meta, trocá-los por outros. Quanto à mudança de meta é o que constitui o essencial da sublimação.

Laplanche fez uma analogia com a faca de Jeanot que, no contexto do design, torna a compreensão mais fácil:

Diante disso podemos fazer analogia com a situação da "faca de Jeannot". É aquela faca que se muda a lâmina e continua sendo a faca de Jeannot; depois muda-se também o cabo, fica sendo ainda a faca de Jeannot; trocase a bainha e tudo foi mudado; mas permanece ainda sendo a faca de Jeannot e, no entanto, nada sobrou dela. Quer dizer que a pulsão continua sendo a mesma, que é sempre energia sexual que está na base da atividade sublimada. (LAPLANCHE, 1989, p. 21). 
Segundo as contribuições freudianas para o processo de criação, a força que impele o sujeito à criação é pulsional. Além dos impulsos plenos de desejos, entra nos processos de criação, tudo que o homem sabe, os conhecimentos, as conjecturas, as propostas, as dúvidas, tudo o que ele pensa e imagina. Falando de maneira bem ampla, na área do design, este processo começa na esfera da criação ao ter uma ideia, depois há um desenvolvimento desta ideia no processo metodológico que resulta em uma objeto de design, um produto desse processo. Podemos então dizer que o processo de criação se inicia com uma tensão psíquica, um acúmulo de energia necessário para levar a efeito uma ação, ou seja, a pulsão impelindo o agir para alcançar o gozo. Depois uma substituição do objetivo da pulsão por outro mais valorizado socialmente através da sublimação que resultará em um produto desse processo, no caso do design, o próprio objeto, produto dessa operação.

Em seu trabalho de releitura da obra freudiana, Lacan aborda o conceito de sublimação principalmente no O Seminário, livro 7: A ética da psicanálise (1959-1960) para pensá-la fora de uma moral adaptativa, não reduzindo-a à busca de uma boa adaptação social, muito pelo contrário, Lacan se volta para o centro da economia libidinal ao propor a revisitação da noção fundamental de das Ding, a Coisa.

Das Ding (a Coisa) é, para Freud, o objeto perdido miticamente na primeira experiência de satisfação. $O$ bebê nasce e tem sua primeira experiência de satisfação. Com frio, fome ele recebe o seio que supre sua necessidade. Quando novamente essa sensação de desconforto aparece, o bebê chora, esperneia pelo objeto que "satisfará" novamente sua necessidade se tornando uma experiência mítica de satisfação que Freud vai enfatizar, em seu texto "Projeto para uma psicologia científica" (1895). Segundo Freud a primeira experiência de satisfação imprime traços no psiquismo e, quando alguma experiência de desconforto se presentifica, há um apelo (grito) ao outro e esse outro dá um sentido a esse apelo, relacionando-o à fome, à dor, ao frio, etc. Partindo dessa primeira experiência de satisfação podemos dizer que dela resta um traço mnêmico permanente que articula a excitação de necessidade (fome) e a "percepção" de um objeto que a satisfaz (seio).

Posteriormente, ao longo da vida, há uma tentativa de resgate, de reencontro dessa primeira experiência. Mas, como sabemos, nessa primeira experiência mítica, algo foi perdido, algo que não pôde ser representado, um resto, que se constitui como ponto de furo no psiquismo, que causa no sujeito a busca de um reencontro do objeto perdido. "Logo, o objetivo dessa primeira atividade psíquica era produzir uma 'identidade perceptiva' - uma repetição da percepção vinculada à satisfação da necessidade". (FREUD, 1895, p. 595).

É em torno da Coisa, para psicanálise, que o processo de criação se estabelece e em torno do vazio deixado pela Coisa, que os objetos de design são criados. É nessa busca de preencher o vazio deixado pela Coisa que o desejo pode advir. Essa parte que se perde da primeira experiência de satisfação, Freud a chamou de vazio por excelência, que não pode ser preenchido por nenhum outro objeto. "Para a psicanálise este objeto não é empírico, não tem substância, a não ser de gozo: trata-se de uma substância episódica". (QUINET, 2004, p. 52). O sujeito desejante pode, através do olhar para o objeto sensível, ter a sensação de gozo pela coisicidade da Coisa que o atravessou. A coisicidade da Coisa não pode se apresentar a não ser pelas Coisas que a representam inscrevendo sempre a falta. "A Coisa pode ser figurada: um objeto qualquer pode tomar a figura evocativa da Coisa". (idem, ibidem, p.57). 
Um objeto comum do mundo sensível que é um objeto empírico, percebido, cognoscível que podemos ver, tocar e entender sua substância se torna substituto do objeto de gozo. Através do processo sublimatório um objeto ganha um valor de representação da Coisa e o que eleva um objeto cotidiano qualquer à dignidade da Coisa é a sublimação.

Um exemplo disto na arte é o urinol de Duchamp. Antes de prosseguir, é válido lembrar que a arte, neste trabalho é um paradigma do design no que tange à criação.

Em 1917, o artista escandalizou e causou estranhamento ao enviar sua obra Fonte para o Salão dos Independentes. Sua obra era um urinol masculino de cabeça para baixo assinado por R. Mutt, seu pseudônimo. Um objeto cotidiano qualquer elevado ao estatuto da Coisa, da obra de arte. O comitê recusou sua obra por não conseguir entender que a elevação do objeto ao patamar de arte se deu através da escolha do artista, do seu olhar. "Ele pegou uma coisa comum da vida e situou-a de forma tal que sua significação habitual desapareceu sob novo título e ponto de vista". (SHORT apud COUTINHO JORGE, 2011, p. 157). O ready-made de Duchamp mostrou de dentro do campo do representável apontando para o irrepresentável. Segundo Marco Antônio Coutinho Jorge (2003) "esse irrepresentável, esse outro lugar, esse mais-além que a obra não pode representar, ela só pode - e deve - evocar: trata-se da absoluta extimidade do objeto" (idem, ibidem, p. 184), que segundo Lacan é o que pertence simultaneamente, ao mais íntimo e ao mais exterior do sujeito.

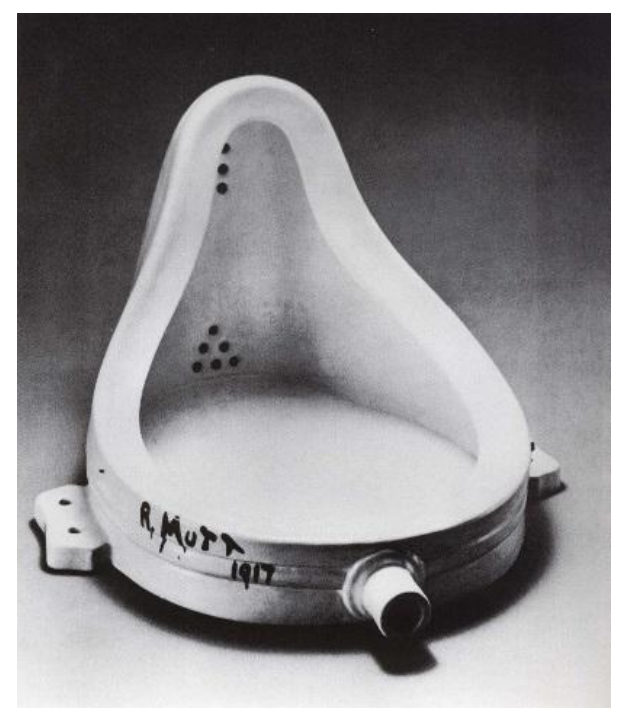

Figura 2 - DUCHAMP, Fonte. 1917 em http://www.philamuseum.org/collections.

No campo do design, onde a forma segue a função, os objetos de design recebem uma nova configuração estética e funcional para atender ao mercado consumidor, mas quando esse objeto comum que possui forma-função é elevado à dignidade da Coisa desperta o desejo dos sujeitos, pois está na extimidade do objeto, tal qual objeto de arte. Um exemplo é a Aranha de Philippe Starck, um espremedor de laranja, objeto comum do cotidiano elevado à dignidade de objeto que causa desejo, à dignidade de Coisa. 


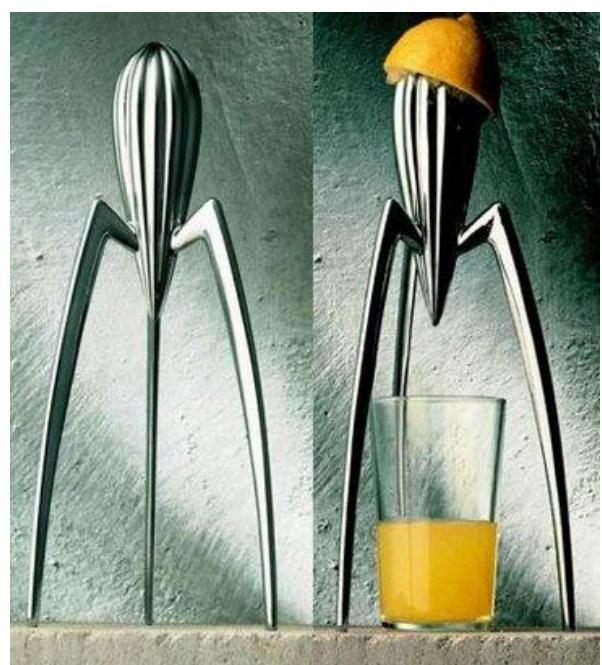

Figura 3 - Espremedor de laranja - Aranha de Philippe Starck em http://www.starck.com/en/

O processo criativo cria o novo. Um objeto que seria uma elaboração ou imitação de algo conhecido, mas inerente a ele tem uma Coisa que nos afeta: a Coisicidade da Coisa, algo que, como vimos, nos provoque sensação de gozo. Não é um objeto da sensibilidade, no entanto possui uma substância episódica de gozo. "É por ele ser circundado pela pulsão que corresponde à recuperação de gozo, ao retorno de gozo perdido da Coisa". (QUINET, 2004, p. 59).

Os objetos de design "mantém certa relação com a Coisa que é feita simultaneamente para cingir, para presentificar e para ausentificar". (LACAN, 19591960 , p. 176) No momento em que o espremedor de laranjas de Philippe Starck é criado, vemos que o designer faz algo bem diferente do que imitar um espremedor de laranjas ou mesmo redesenha-lo. Ele faz surgir um objeto de maneira que constitui uma renovação de sua dignidade. Eleva o objeto, neste caso o espremedor de laranjas, à dignidade de representante da Coisa despertando o desejo nos sujeitos consumidores.

O desejo é o motor que alimenta o processo criativo tanto nos criadores quanto nos sujeitos que consomem estes objetos criados. O criador, no nosso caso, o designer, "após ter operado no plano da sublimação, é beneficiário de sua operação uma vez que ela é reconhecida em seguida, recolhendo precisamente sob a forma de glória, honra e até mesmo de dinheiro, as satisfações fantasiosas" (idem, ibidem, p. 180) que estavam presentes desde o início da operação de busca de satisfação de suas pulsões pela via da sublimação. O desejo em busca de realização profissional, de ascensão social e reconhecimento.

Quanto aos sujeitos que consomem os objetos de design, são sujeitos desejantes e, como tal, encontram no objeto de design algo que se coloca no lugar do objeto perdido gerando uma satisfação mesmo que momentânea e efêmera. Em ambos os casos é o desejo que move todo o processo criativo.

O processo criativo implica um sujeito com suas particularidades e o que promove tal processo é o desejo, o que um sujeito tem de mais particular. O desejo não só gera o processo de criação como também movimenta o designer quanto a sua criação para que esta seja desejada pelos consumidores que, por sua vez, são sujeitos desejantes.

Deste modo, o processo criativo em design é semelhante à criação artística. É pulsional e se destina sublimatoriamente contornando o vazio deixado pela Coisa. É o 
epicentro em que gravitam todos os representantes da representação da Coisa que não pode ser representada, ou como diz Lacan, que só pode ser representadas por outra Coisa. Cada objeto de design tem em si uma representação da Coisa, algo indecifrável, mas que nos causa abrilhantamento. Uma coisicidade em si que desperta no consumidor o desejo.

Entender que o vazio da Coisa dá início ao processo de criação artística e perceber que o mesmo vazio constituinte do sujeito move o designer em sua produção é desvendar o que está por trás do desejo do mercado consumidor, onde o sujeito busca ser o desejo do desejo do outro. O objeto criado pelo designer deixa de ser somente desejado para assumir o valor de desejo do desejo do Outro. Há nele uma inscrição da falta do sujeito que o criou e reconhecida de alguma forma pelo sujeito que o deseja.

\section{Processos inconscientes como diferencial no processo metodológico de design}

Os estudos psicanalíticos sobre a criação artística ofereceram suporte para construir um novo olhar para a metodologia a ser aplicada no processo projetual em design. Segue-se algumas reflexões para uma mudança na metodologia de ensino propostas depois da contribuição da psicanálise sobre o entendimento da falta, constituinte do sujeito, que está na base da criação.

$\mathrm{O}$ design tem sua base de construção fundamentada em metodologias que tornam seus processos comunicáveis, porém, quando se trata de uma investigação a respeito de metodologias de design, é comum se ter como resultado uma longa lista de autores com seus esquemas e processos. Bürdek (2006), no entanto, afirma que o design é um processo criativo. Cada resultado advém de um processo de desenvolvimento e seu andamento é determinado por condições e decisões do sujeito envolvido no processo, não apenas a configuração metodológica em si.

Partindo do processo metodológico como processo criativo enriquecido pelas contribuições psicanalíticas propomos uma metodologia que não se fixe apenas na solução de problemas, mas forneça meios pelos quais esse sujeito envolvido no processo, possa se satisfazer na busca pela solução dos problemas. Embora saibamos que essa satisfação não poderá ser plenamente satisfeita o designer, envolvido em seu processo de criação, realiza parcialmente seus desejos ao criar algo novo.

Nesta nova forma de construção do processo criativo como metodologia projetual, tudo está aberto ao sujeito que é o ator e autor do seu próprio processo. À luz da psicanálise podemos compreender que os processos de criação representam, na origem, tentativas de reestruturação, de satisfação e realização do sujeito diante do que Ihe falta. São processos produtivos onde esse designer se surpreende e se descobre.

Nesta nova proposta, nada poderia ser fixo e conhecido, e se assim fosse, acabaria com o próprio ato de criar, "dar existência, sair do nada (ex nihilo), estabelecer relações até então não estabelecidas pelo sujeito". (NOVAES, 1972, p. 17). O processo criativo não poderia obedecer a um único modelo, já que cada um tem suas habilidades, competências e seus métodos. O designer tem algo particular para oferecer ao mercado consumidor. Algo próprio que será partilhado por outros sujeitos através de uma identificação. 
Esta identificação pode se dar por diferentes fatores, pelo material, por um elemento que está no projeto, ou ainda por um valor intangível que esse projeto transmitiu aos sujeitos consumidores. A cada projeto de design, que apresenta algo novo, leva o sujeito a um abrilhantamento, um estado de gozo. O mercado consumidor espera gozar com os objetos de design por isso os consomem.

O designer, guiado pela força pulsional, vai contornar esse objeto da falta, objeto que causa o desejo, colocando em seu lugar um objeto de design despertando assim o desejo do mercado consumidor. Esses objetos de design são, portanto objetos substitutos do objeto perdido, objetos a serem colocados no lugar do vazio deixado pela falta constituinte do sujeito. Um objeto que represente algo para o seu criador e seduza outras pessoas ao despertar seus desejos.

No processo de criação desses objetos de design, o sujeito se vê diante de encruzilhadas, em uma busca que não se esgota. Propondo, optando, prosseguindo, ele é impelido por uma força pulsional que o guia e o induz. E no final, quando o objeto se materializar, o processo de criação terá produzido um mais de gozar.

Esta nova metodologia ainda está em construção e exige muita coragem e experimentações, algumas delas serão apresentadas a partir de agora para reflexão e, quem sabe, encontrar contribuições para seu desenvolvimento.

Uma das primeiras experimentações se deu em torno do briefing do projeto. Os estudantes foram convocados a refletir e entender as demandas dos usuário. Através de pesquisas, e utilização do mapa da empatia ${ }^{2}$, havia a tentativa era perceber para além do enunciado pela pessoa pra quem se vai projetar. Foram convocados a perceber o a enunciação, e não o que está sendo dito, a demanda oculta desses sujeitos. O que não é falado mas é percebido através de sinais repetidos da subjetividade para o social.

Ao compreender que existe algo que está subintendido na comunicação entre os sujeitos, o designer pode ressignificar o que vai projetar. Neste momento estava sendo solicitado aos estudantes, dar um novo sentido à fala do usuário. Como, por exemplo, quando estamos com uma pessoa ao telefone e perguntamos se está tudo bem. A resposta pode ser afirmativa, mas o tom da voz diz que a resposta correta é negativa. Com ajuda da psicanálise, entendemos que essa demanda oculta é a fala em direção ao outro na busca do objeto perdido que taparia sua falta. O que o designer vai projetar para esse usuário é algo que atenda à falta que é demandada pelo mercado consumidor.

Outra experimentação surgiu da necessidade de flexibilização da barra da censura consciente, para que o inconsciente pudesse resvalar no processo de criação. Depois do briefing do cliente é necessário um tempo de atividade onde o inconsciente sem limites, desimpedido pelo intelecto literal, que faz inesperadas conexões que constituem a essência da criação. (KNELLER, 1978, p. 67).

No caso do processo criativo em design, é a hora de deixar-se levar pela Coisa que chama. Foi utilizado o conhecido brainstorming, só que com uma aplicação diferenciada de determinar a natureza do problema. Foi utilizado para flexibilizar essa barreira entre o consciente e o inconsciente. No brainstorming, as enunciações são expressas sem que o sujeito tenha que agir com inteligência sobre o assunto ou sobre

\footnotetext{
${ }^{2}$ O Mapa de Empatia é uma ferramenta visual que foi desenvolvida pela XPLANE para ajudar na visualização de um perfil de cliente. A ferramenta é pensada de forma que você seja capaz de estruturar um perfil para começar o projeto.
} 
as próprias enunciações, algo análogo ao que se chama de associação livre, técnica elaborada por Freud que teve importância para construção da psicanálise. Uma fala lacunar, partida, sem sequência de causalidade esperada na fala comum. Ele fazia seus pacientes assumirem o compromisso de se absterem de qualquer reflexão consciente e se abandonarem em um estado de tranquila concentração, para seguir as ideias que espontaneamente (involuntariamente) lhe ocorressem - "a escumarem a superfície de suas consciências". (FREUD, 1923-1924, p. 219).

$\mathrm{Na}$ associação livre o conteúdo é aparentemente irrelevante, sua determinação deve vir de outro lugar, não da consciência. No primeiro momento, não se dá importância ao conteúdo, nem às concatenações entre as ideias, assim como ocorre no brainstorming. Esses conteúdos vêm de outro lugar, do que Freud chamou de inconsciente. No inconsciente, predomina uma outra lógica, que não é a da consciência, em que algo pode ser e não ser, sob o mesmo aspecto. E assim que se buscam nesse outro lugar, de uma outra lógica, conteúdos que serão trabalhados depois, sob a lógica da consciência, da concatenação e da ordem. Dessa elaboração muitas ideias divergentes nascem de um conflito interno do sujeito fornecendo um material riquíssimo para ser trabalhado durante o processo de criação.

Ao associar livremente no brainstorming, os significantes vão sendo ditos em relação a outros significantes e o possível significado do significante que deu início ao brainstorming se extingue imediatamente mostrando que "nenhuma significação se sustenta a não ser pela remissão à outra significação". (LACAN, 1966, p. 501).

O nosso inconsciente vai de significante em significante em busca de significação, "pois o significante, por sua natureza, sempre se antecipa ao sentido, desdobrando como que adiante dele sua dimensão". (idem, ibidem, p. 501).

Uma imagem que tenha achado fantástica, uma música que se pegou cantarolando, um filme que lembrou. O que comparece é bem-vindo, sem julgamentos. São estes fragmentos de imagens aparentemente sem sentido se articularão entre o princípio do processo e a manifestação dos seus efeitos sobre o objeto de design. São esses fragmentos subjetivos oriundos da criação que construirão um processo metodológico particular para cada designer.

\section{CONCLUSÃO}

Neste artigo, ao aproximar duas diferentes áreas de conhecimento, ao utilizar a natureza da criação artística sob o olhar psicanalítico como paradigma da metodologia projetual em design, houve o enriquecimento da compreensão deste processo.

O que motivou o estudo do processo criativo, foi a vontade de apreendê-lo. Dominar o processo para ensiná-lo. O encontro com a psicanálise trouxe uma percepção diferenciada. No processo criativo, não há quem ensine e não há quem aprenda, pois é impossível dessas tarefas se realizarem. Existe apenas a compreensão do processo.

A psicanálise fez ver o estudante de design, enquanto sujeito constituído pela falta, capaz de perceber o mundo de forma própria, colorindo-o com significações diversas dando-lhe um novo sentido. Para dar sentido esse designer coloca em jogo sua subjetividade no fazer criador. É este fazer, essa potência subjetiva, que 
transforma a criatividade em realização. O designer é constituído por um vazio que busca o preenchimento desse lugar com a criação dos objetos de design.

O conceito de sublimação foi vital para entender como o sujeito, ao criar um objeto de design, pode propiciar uma substituição de objetos para "realização" dos desejos dos sujeitos consumidores. O resultado da sublimação como desvio da energia libidinal de suas metas originais é investida em realizações culturais, ou em realizações individuais compartilháveis aos grupos sociais.

O desejo é o motor que alimenta o processo criativo tanto nos criadores quanto nos sujeitos que consomem estes objetos criados. O criador, no nosso caso, o designer, após ter operado no plano da sublimação, é beneficiário de sua operação uma vez que ela é reconhecida em seguida, ele recolhe precisamente sob a forma de glória, honra e até mesmo de dinheiro, as satisfações fantasiosas que estavam presentes desde o início da operação de busca de satisfação de suas pulsões pela via da sublimação.

O processo de criação como metodologia projetual é entendido como a mudança ou ampliação do olhar e não na estagnação das fórmulas e mecanismos de interpretação da realidade. Ao criar o sujeito passa do estado de não ser (estando na falta) ao estado de ser quando destrói, constrói e se transforma com o que destruiu. A partir do objeto que criou o sujeito se torna o desejo de outro desejo ao inventar um objeto numa função especial, que a sociedade pode estimar valorizar e aprovar.

O processo criativo em design é semelhante à criação artística. É pulsional e se destina sublimatoriamente contornando o vazio deixado pela Coisa. É o epicentro em que gravitam todos os representantes da representação da Coisa que não pode ser representada, ou como diz Lacan, que só pode ser representadas por outra coisa. Cada objeto de design tem em si uma representação da Coisa, algo indecifrável, mas que nos causa abrilhantamento. Uma coisicidade em si que desperta no consumidor o desejo.

As ferramentas de criatividade estão sendo abordadas e experimentadas com as contribuições psicanalíticas incentivando cada estudante de design a elaborar seu próprio "modus operandi" a fim de conseguir um resultado particular e diferenciado no modo de projetar.

Propostas como essas evidenciam a possibilidade de trazer o "saber" de outras áreas do conhecimento para o design. Essas iniciativas proporcionam a oportunidade de estender o campo do design em novas abordagens. O lugar da acentuada orientação técnica encontrada em boa parte dos nossos cursos pode estar amalgamado com questões de outros campos do saber, neste caso a psicanálise veio contribuir para subjetivação do processo metodológico em design através da sublimação.

\section{REFERÊNCIAS}

BÜRDEK, B. E. História, teoria e prática do design de produtos. São Paulo: Edgard Blücher, 2006.

COUTINHO JORGE, Marco Antonio. A pulsão de morte. In: Estudos de Psicanálise Revista do Círculo, Brasileiro de Psicanálise. Belo Horizonte, n.26, 2003. 
FREUD, Sigmund. (1905) Três ensaios sobre a teoria da sexualidade. In: Edição Standard Brasileira das Obras Psicológicas Completas de Sigmund Freud (ESB). Rio de Janeiro: Imago, 1996. Vol. 7. . (1950 [1895]) Projeto para uma psicologia científica. In: ESB, op. cit. Vol. 1. (1926) Inibição, sintoma e angústia. In: ESB, op. cit. Vol. 20. . (1950 [1895]) Projeto para uma psicologia científica. In: ESB, op. cit. Vol. 1.

KNELLER, George. Arte e ciência da criatividade. São Paulo: Cultrix, 1978.

LACAN, Jacques. (1959-1960) O Seminário, livro 7: A ética da psicanálise. Rio de Janeiro: Jorge Zahar Editor. (1966) Escritos. Rio de Janeiro: Jorge Zahar Editor.

LAPLANCHE, Jean. A sublimação. São Paulo: Martins Fontes, 1989.

NOVAES, Maria Helena. Psicologia da criatividade. Rio de Janeiro: Vozes, 1972.

QUINET, Antonio. Um olhar a mais: Ver e ser visto na psicanálise. 2a ed. Rio de Janeiro: Jorge Zahar Editor, 2004. 